\title{
Variação gráfica em manuscritos oitocentistas da camara municipal de Rio Pardo (RS)
}

\author{
Graphic variation in eighth-century manuscripts \\ of the municipal council of the Rio Pardo (RS)
}

Leici Landherr Moreira

Universidade Federal de Santa Maria (UFSM)

Evellyne Patrícia Figueiredo de Sousa Costa

Universidade Federal de Santa Maria (UFSM)

DOI: https://doi.org/10.5902/2176148542769

Resumo: Este trabalho pretende analisar a variação gráfica de hipossegmentação em manuscritos oitocentistas, sob a perspectiva teórica da Sociolinguística Histórica. Acreditamos que a ocorrência desse fenômeno tenha uma motivação linguística de ordem prosódica e sóciohistórica. Analisamos 410 ocorrências de hipossegmentações e os resultados indicam que a motivação linguística é o fato de o escrevente perceber a existência do hospedeiro e do clítico, mas assinalar a dependência prosódica do clítico em relação ao hospedeiro, registrando, assim, uma frase fonológica. A motivação sócio-histórica é paleográfica, pois a forma do elemento gráfico, se possui ou não traçado contínuo, pode influenciar na formação de hipossegmentações. Palavras-chave: Variação gráfica. Rio Pardo. Hipossegmentação. Sociolinguística Histórica.

Abstract: The aim of this research is to analyse a hypo-segmentation in nineteenthcentury manuscripts under the theoretical contribution of the Historical Sociolinguistics. We believe that the phenomenon of hypo-segmentation presents a social-historical and linguistic motivation of prosodic nature. We analyse 410 occurrences of hypo-segmentation and the results indicate that a linguistic motivation for the phenomenon would consist in the fact of the clerk perceiving the presence of host and clitic, but verifying the prosodic dependence of the clitic on the host, thus recording a phonological sentence. The socialhistorical motivation is paleographic, because the shape of the graphic element, whether or not it has a continuous outline, can influence the formation of the hypo-segmentations. Keywords: Graphic variation. Rio Pardo. Hypo-segmentation. Historical Sociolinguistics.

1 Este artigo é um recorte da dissertação de mestrado intitulada Hipossegmentações em manuscritos oitocentistas da Câmara Municipal de Rio Pardo (RS), vinculada ao Programa de Pós-Graduação em Letras da Universidade Federal de Santa Maria. 
Leici Landherr

Moreira

Evellyne

Patrícia

Figueiredo de

Sousa Costa

\section{Introdução}

O registro escrito é uma das fontes de pesquisa mais importante para o conhecimento da história das línguas. Barbosa (2008, p. 181) considera que, antes da invenção da gravação magnetofônica, "só há história de uma língua se houver textos, [...] e textos escritos nessa mesma língua". É nesse sentido que nossa investigação começa pela tarefa de leitura e edição dos textos antigos, pois sem o estabelecimento do texto dos manuscritos, através da Crítica Textual que fornece um testemunho fidedigno do registro escrito, a identificação dos dados torna-se praticamente impossível. No corpus de 28 documentos oficiais da Câmara Municipal de Rio Pardo escritos em 1812 pelo procurador da Câmara, Manoel Bento Ferreira da Gama, e pelo escrivão, Leocadio Maximo de Souza, interessa-nos examinar um tipo de variação gráfica: a hipossegmentação, que é a supressão do espaço em branco entre palavras, que são grafadas de modo contínuo, eliminando a fronteira vocabular, como em 'lhedeferirem' (Ofício 2, 1. 12), ‘doCostume' (Ofício 2, 1. 13).

Estudos sobre as variantes gráficas em textos de sincronias passadas interpretam os grafemas como reflexo da fala, sob a perspectiva da mudança linguística e de teorias fonológicas, como em Telles e Lose (2010), Monaretto (2005), Nasi (2016), Ribeiro (2018); ou, partindo de princípios filológicos, analisam o uso dos grafemas enquanto prática de escrita de um grupo da sociedade em determinada época (MEGALE et al., 2007; FACHIN, 2011). Em nosso trabalho, analisaremos o fenômeno de hipossegmentação sob a perspectiva teórica da Sociolinguística Histórica com o propósito de identificar motivações linguísticas e sócio-históricas que expliquem a ocorrência desse fenômeno em documentos oficiais oitocentistas de Rio Pardo.

\section{Rio Pardo, a tranqueira ${ }^{2}$ invicta}

A origem da cidade de Rio Pardo é vinculada ao Tratado de Madri de 1750 (VOGT; ROMERO, 2010). Em virtude desse tratado, as tropas portuguesas deveriam seguir em direção às missões a fim de se apossarem da região dos Sete Povos, expulsando seus habitantes. Para o apoio das tropas, em 1751, o Capitão-General da Capitania do Rio de Janeiro, Gomes Freire de Andrade, ordenou a criação de dois depósitos de

2 Segundo Maestri (2010, p. 25), tranqueira refere-se a uma estacada (cerca de madeira feita de estacas) construída para fortificação. 
munição e de víveres. Rio Pardo foi indicado por Francisco Manoel de Távora, furriel do Regimento de Dragões, como um dos locais estratégicos por conta da sua localização na margem esquerda da confluência dos rios Pardo e Jacuí. Tratava-se de um ponto estratégico na fronteira extremo-oeste devido à sua localização elevada com ampla visão dos arredores e devido à sua hidrografia, pois os rios formavam barreiras naturais instransponíveis às investidas de seus inimigos, daí a denominação "tranqueira invicta". o forte representava a posição mais extrema dos portugueses em direção às missões e desempenhava a função de impedir a passagem dos índios missioneiros que pretendiam atacar os campos de Viamão. Por isso, Gomes Freire determinou a construção do Forte de "Jesus, Maria, José" em Rio Pardo, onde o Regimento de Dragões instalou-se posteriormente (VOGT; ROMERO,

Variação gráfica em manuscritos oitocentistas da câmara municipal de Rio Pardo (RS) 2010, p. 19). A população civil (tropeiros, comerciantes e açorianos), em busca de segurança, aproximou-se do Forte, dando origem a um povoado (MEISTER, 2017) que se tornou a freguesia de Nossa Senhora do Rosário do Rio Pardo em 1769.

No entanto, só dois anos após a criação da capitania do Rio Grande de São Pedro em 1809, foi nomeada Vila de Nossa Senhora do Rosário de Rio Pardo, juntamente com Rio Grande, Porto Alegre e Santo Antônio da Patrulha na primeira divisão do estado pela provisão de 7 de outubro de 1809. A Vila de Nossa Senhora do Rosário de Rio Pardo instalou-se solenemente em 20 de maio de 1811 com a criação da Câmara Municipal, abertura de "Pelouros" dos juízes vereadores e mais oficiais, além do deferimento do juramento dos Santos Evangelhos aos funcionários de justiça nomeados (LAYTANO, 1976, p. 186).

No período colonial, as Câmaras tinham seus cargos ocupados por indivíduos designados homens bons, ou seja, integrantes das elites socioeconômicas locais, que deveriam responder a alguns requisitos: maiores de 25 anos, casados ou emancipados, sem nenhuma "impureza de sangue" (mestiçagem racial), católicos, proprietários de terra (COMISSOLI, 2006, p. 21). De acordo com Comissoli (2006, p. 22), a Câmara era composta por dois tipos de membros. Primeiramente, o cargo de oficial era formado por cargos eletivos com direito a voto, seus ocupantes não recebiam remuneração, somente um certo grau de prestígio. Os cargos de oficiais eram ocupados por dois juízes ordinários (não necessariamente com formação em Direito), dois a quatro vereadores e um procurador (responsável pelas finanças). Em segundo lugar, havia 


\section{Leici Landherr}

Moreira

Evellyne

Patrícia

Figueiredo de

Sousa Costa

134

cargos menores como o de juiz vintenário, juiz almotacé, juiz de órfãos, escrivão, porteiro, carcereiro e tesoureiro, todos indicados pelos oficiais da Câmara, e ainda que não concedesse direito a voto, o cargo dispunha de remuneração para realizar atividades complementares às funções dos oficiais.

O processo de eleição para os cargos camarários de oficiais se realizava a cada três anos. Conforme Comissoli (2006, p. 23),

[...] em um primeiro momento, o conjunto dos "homens bons" elegia seis representantes dentre seus pares, designados eleitores. Estes eleitores eram distribuídos em duplas, cada dupla era responsável por realizar uma lista com os nomes dos "homens bons" que deveriam ocupar os cargos camarários. As três listas produzidas eram fechadas em bolas de cera (pelouros) e guardadas dentro de um cofre. No final de cada ano, um menino aleatoriamente escolhido retirava um dos pelouros, que era então aberto e tinha sua lista revelada. Os nomes contidos na lista seriam os ocupantes dos cargos no ano vindouro, chamados de oficiais de pelouro. Eventualmente, quando um indivíduo não assumia por qualquer motivo, os oficiais camarários nomeavam um substituto, chamado oficial de barrete.

Em Rio Pardo, pelo sistema de pelouro, foram eleitos os oficiais membros da Câmara Municipal, então composta por dois juízes ordinários, três vereadores e um procurador, e depois, a própria Câmara elegeria os demais oficiais como o juiz de órfãos, escrivães, tesoureiros e juízes almotacés (SCHMACHTENBERG, 2018, p. 177). No final de 1811, o pelouro foi aberto, sendo eleitos para juízes ordinários, o Capitão Manoel Thomás de Nascimento e o Tenente Jose Martins da Crus; para vereadores, o Capitão Antonio Gonsalves da Cunha, Antonio Coelho Leal, Manoel Alvares de Oliveira; para procurador, o Alferes Manoel Bento Ferreira da Gama3. Mais tarde, Leocadio Maximo de Souza, um dos escreventes dos documentos que compõe o corpus dessa pesquisa, foi eleito para o cargo de escrivão da Câmara ${ }^{4}$.

3 Livro de Posses e Juramentos (LPJ), n. 2, 1811/1841.

4 Para ver um quadro completo dos cargos ocupados na Câmara em 1812, cf. Moreira (2019, p. 32). 


\section{Referencial teórico}

Nos textos manuscritos de épocas passadas, verificamos duas formas ou variantes de grafar a segmentação: a hipersegmentação e a hipossegmentação. A hipossegmentação resulta da supressão do espaço em branco entre palavras, que são grafadas de modo contínuo, eliminando a fronteira vocabular, enquanto a hipersegmentação decorre da inserção de espaço em branco entre elementos não separáveis. A escrita de palavras sem supressão de espaço é uma prática antiga, intitulada scriptio continua, frequente nos textos a partir do século II, até a imposição do espaçamento no início da Idade Média. Em língua portuguesa, esse tipo de escrita aparece em textos dos séculos IX, X e XI: “os documentos portugueses dos séculos IX, X e XI, em letra gótica, são de difícil leitura, em virtude da separação dos elementos da palavra ou a união de palavras diversas numa só" (SPINA, 1977, p. 42-43)". No século XIX, ainda encontramos hipossegmentações nos manuscritos que compõem o corpus desse trabalho.

A explicação para a ocorrência desse tipo de fenômeno não é um ponto pacífico entre os estudiosos. Mendes, Dores e Gomes (2017, p. 44) consideram a "necessidade de agilizar o processo de escrita, principalmente por se tratar de letras cursivas, e/ou economizar material, uma vez que o ato de levantar a pena da superfície do papel resulta em maior gasto de tempo, de tinta e do próprio suporte utilizado para escrever". Esses autores também atribuem à presença da oralidade na escrita como outra explicação possível para a ocorrência de hipossegmentação. Nesse caso, o escrevente registraria as palavras ou conjunto de palavras conforme sua pronúncia, registrando, portanto, a palavra fonológica. Nessa mesma perspectiva está o estudo de Kajita (2009), para quem muitos casos de hipossegmentações com nomes/verbos e artigos/preposições revelam que a nova segmentação em geral coincide com a noção de palavra fonológica. Battisti (2013) argumenta que a hipossegmentação pode ser um indício de que o escrevente não perceba a presença do clítico ${ }^{5}$, sendo a sequência usada como uma unidade lexical (detarde, de tarde), ou de que, percebendo o clítico, assinale sua depen-

5 O clítico é uma forma que nunca ocorre isoladamente, "mas pode aparecer ligada a outra que não é aquela que a condiciona, quando entre ela e a sua condicionante se intercalam livremente outras formas" (CÂMARA JR, 1964, p. 88). Em língua portuguesa, os clíticos são: artigos (o, a, um, uma), preposição (de, em, sem, com, por, a, entre, para), pronome pessoal (se, me, te, nos, o, a, lhe), conjunção (e, mas, ou, se), pronome ou conjunção (que, porque, cada) (BISOL, 2005, p. 164). 
Leici Landherr

Moreira

Evellyne

Patrícia

Figueiredo de

Sousa Costa

136 dência prosódica em relação ao hospedeiro (oBarão, o Barão). Megale et al. (2007, p. 132), por sua vez, atribuem a ausência de fronteira entre vocábulos ao fato de a letra possuir um traçado corrente à mão, que ligaria os grafemas enquanto são escritos. Assim, o escriba só levantaria a caneta/pena para reabastecer de tinta, caso contrário não haveria a presença de uma fronteira entre palavras de uma escrita encadeada, pelo fluxo da letra cursiva.

Em termos gramaticais, notamos que, no século XIX, não há nenhuma norma oficial da língua portuguesa no Brasil que prescreva o tipo ideal ou "correto" de segmentação das palavras ou conjunto de palavras. Verificamos que as ortografias setecentistas portuguesas ${ }^{6}$ tratam da forma de segmentação das palavras escritas, sobretudo em relação às preposições, advérbios, interjeições e conjunções, no entanto não há como verificar o alcance dos manuais ortográficos e sua possível circulação na sociedade oitocentista sul-rio-grandense. Ademais, não há muitos estudos acerca da descrição da língua portuguesa no século XIX no Rio Grande do Sul que possam estabelecer a tradição da escrita desse período de modo que explique a ocorrência de hipossegmentações. ${ }^{7}$ Por essas razões, lançamos mão do aporte teórico da Sociolinguística Histórica, pois acreditamos que essa teoria permite caracterizar a hipossegmentação em seu contexto sócio-histórico na medida em que possibilita caracterizar a comunidade linguística, estabelecer o perfil sociocultural dos escreventes e fixar critérios metodológicos para o trabalho com sincronias pretéritas.

\subsection{Sociolinguística Histórica}

A Sociolinguística Histórica se preocupa em descrever e em explicar os fenômenos de variação e de mudança pela correlação entre fatores linguísticos e sociais analisados em registros escritos antigos (CONDE-SILVESTRE, 2007). Esta disciplina está alicerçada no princípio do uniformitarismo, que prevê o conhecimento dos processos que operaram no passado pela observação de processos em andamento no presente (LABOV, 1999, p. 21, 1975). Com seu trabalho fundacional, Romaine (1982) inaugurou a teoria ao propor a utilização dos métodos de análise variacionista para investigar processos de variação e mudança de fenô-

Cf. Feijó (1734, p. 130), Monte Carmelo (1767, p. 461), Argote (1725, p. 288-289).

Ver, por exemplo, Nasi (2012, 2016), Silva (2013), Pereira (2017), Ribeiro (2018). 
menos linguísticos em textos antigos. A linguista analisou processos de variação do conector relativo do Escocês Médio em amostras de língua escrita de 1530-50 e percebeu que a variação correlacionava fatores linguísticos, tais como características do antecedente, posição sintática do marcador relativo na oração relativa, tipo de oração, e fatores extralinguísticos (ou sociais) como tipo de texto (prosa/verso) e estilo do texto.

Em nosso trabalho, lançamos mão das orientações teórico-metodológicas propostas pela Sociolinguística Histórica concernentes às dificuldades enfrentadas na construção do corpus de pesquisa, à identificação/reconstrução das variáveis sócio-históricas e ao estabelecimento das variáveis linguísticas. A primeira dificuldade do pesquisador é construir um corpus com textos escritos em tempos passados, principalmente, porque a pesquisa depende da recuperação de fenômenos

Variação gráfica em manuscritos oitocentistas da câmara municipal de Rio Pardo (RS) linguísticos do passado a partir de registros escritos que sobrevivem por acaso em museus e arquivos históricos públicos ou particulares, e, geralmente, não estão em condições favoráveis ao manuseio do pesquisador. Nesse caso, cabe ao pesquisador fazer o "melhor uso dos dados disponíveis" (NEVALAINEN; RAUMOLIN-BRUNBERG, 2017, p. 26), o que requer a sistematização na coleta de dados, várias leituras anteriores e bom trabalho filológico.

Do mesmo modo, é fundamental a reconstrução do perfil sociocultural do escrevente. Apesar de o acesso aos dados sócio-históricos sobre sua origem, escolaridade, faixa etária, profissão etc. ser praticamente inexistente nos registros escritos pelo redator, a abordagem interdisciplinar da Sociolinguística História com outras disciplinas possibilita o preenchimento de lacunas biográficas com informações efetivamente produtivas para a análise do fenômeno considerado. 0 estudo da variação gráfica, como a hipossegmentação, exige, por exemplo, o conhecimento dos aspectos paleográficos da escrita (a morfologia das letras, sua forma, módulo, traçado ou ductus) e da própria prática de escrita dos redatores a fim de verificar se lidavam com a escrita no âmbito de sua profissão.

Paralelamente, há a pesquisa histórica direcionada pela documentação indireta ${ }^{8}$, isto é, em documentos oficiais como os livros sacramentais, certidões de batismo e casamento mantidos em paróquias e igrejas, além dos livros da administração pública que também auxiliam

8 Entendemos por documentação indireta todos os documentos que não integram o corpus de análise, mas apresentam informações a respeito dos escreventes. 
Leici Landherr

Moreira

Evellyne

Patrícia

Figueiredo de

Sousa Costa

na reconstrução de parâmetros extralinguísticos (ESTEBAN-SEGURA, 2012, p. 146). Mas o que não podemos perder de vista é a concepção de perfil sociocultural em trabalhos com sincronias passadas. De acordo com Lopes et al. (2010, p. 240), não devemos "tomar o perfil como uma mera combinação de variáveis sociais, recortadas e concebidas como realidades estanques com sentidos prévios ao contexto em que ocorrem". Para os autores, uma conceituação alterna de perfil sociocultural abrange o cruzamento de perspectivas, que relacionem a trajetória de vida dos escreventes, o contexto de produção dos registros escritos e o mapeamento e descrição das redes de escrita (LOPES et al., 2010, p. 239). Nesse sentido, podemos dizer que a fixação de variáveis sócio-históricas é posterior ao exame meticuloso dos textos que compõem o corpus da pesquisa, da documentação indireta, do contexto de produção dos documentos, e de estudos de cunho sócio-histórico sobre a comunidade linguística de uma determinada época.

O mesmo ocorre com o método de fixação das variáveis linguísticas. De acordo com Morales (2005, p. 15), o pesquisador em Sociolinguística Histórica não detém uma lista predeterminada de variáveis para anotar as diferentes variantes para cada uma delas, uma vez que só pode estabelecer as variáveis linguísticas e as condições sociais das variantes depois de analisar os textos a partir dos dados disponíveis.

Por fim, em razão do princípio do uniformitarismo, vários fenômenos linguísticos do passado continuam ocorrendo modernamente. Por isso, é possível que as teorias modernas que explicam esses fenômenos e suas variáveis também possam ser aplicadas em dados de registros escritos antigos. Nos estudos sobre a hipossegmentação, destaca-se a Fonologia Prosódica.

\subsection{Fonologia Prosódica}

O fenômeno de hipossegmentação continua se realizando na modernidade, sobretudo, no contexto de letramento e de aquisição da escrita. Em tal caso, os pesquisadores, tais como Abaurre (1992), Cunha e Miranda (2009), Ferreiro e Pentecorvo (1996) lançam mão da teoria prosódica para propor uma explicação linguística fundamentada nos constituintes prosódicos.

Segundo a teoria prosódica proposta por Nespor e Vogel (2007, p. 1), a representação mental da fala divide-se em segmentos hierarquicamente organizados, os constituintes prosódicos. Cada constituinte prosódico identifica-se como domínio de aplicação de regras fonológicas e 
processos fonéticos específicos e não apresenta necessariamente isomorfia com constituintes de outras áreas da gramática. Para as autoras (2007, p. 11) a hierarquia prosódica abrange sete unidades, da menor para o maior: sílaba $(\sigma)$, pé $(\Sigma)$, palavra fonológica $(\omega)$, grupo clítico $(C)$, frase fonológica $(\phi)$, frase entonacional (I), enunciado (U). Nos trabalhos a respeito da hipossegmentação, parece não haver dúvidas de que o escrevente, diante da tarefa de segmentar a escrita, apoia-se na percepção de sílaba, pé, palavra prosódica, frase fonológica etc.

Kajita (2009) investiga a segmentação ortográfica não-canônica em textos portugueses de adultos semialfabetizados dos séculos XVII e XVIII, selecionados do arquivo da Inquisição de Lisboa. A autora parte da hipótese de que o texto diacrônico pode apresentar informações fonológicas que variam da pronúncia ao padrão rítmico da língua, por isso

Variação gráfica em manuscritos oitocentistas da câmara municipal de Rio Pardo (RS) defende a relação entre esse tipo de segmentação e a prosódia da língua, validada a partir da análise de evidências na escrita de inábeis. Os resultados de Kajita (2009) revelaram que, em muitos casos de hipossegmentações com nomes/verbos e artigos/preposições, a nova segmentação em geral coincide com a noção de palavra fonológica (2009, p. 16).

Battisti (2013), por sua vez, examina somente as ocorrências de hipossegmentações de sequências com clíticos em documentos do século XIX. Para a autora (BATTISTI, 2013, p. 19), em documentos atuais ou antigos, a hipossegmentação pode ser um indício de que o escrevente não percebe a presença do clítico, sendo a sequência usada como uma unidade lexical (detarde, de tarde), ou de que, percebendo o clítico, assinale sua dependência prosódica em relação ao hospedeiro (oBarão, o Barão). Em seu estudo, estabeleceu os seguintes critérios de análise das formas hipossegmentadas com clíticos em cartas oficiais e não oficiais, escritas em diferentes regiões do país entre 1809 a 1904 (CARNEIRO, 2005), e em 155 exemplares de 8 jornais gaúchos, publicados de 1835 a 1900 (NASI, 2012): a posição do clítico adjungida à esquerda ou direita do hospedeiro; a natureza do clítico enquanto palavra funcional (preposição, conjunção, artigo) e hospedeiro como palavra lexical (verbo, advérbio etc.); a acentuação do hospedeiro, se monossílabo tônico ou dissílabo paroxítono; se o hospedeiro inicia com consoante ou vogal maiúsculas ou minúsculas; a hipossegmentação com a conjunção "e" e mais um clítico para satisfazer a exigência de minimalidade prosódica (dissilabicidade) e para perceber a conjunção como palavra morfológica, uma vez que é um pequeno corpo grafo-fônico. 
Leici Landherr

Moreira

Evellyne

Patrícia

Figueiredo de

Sousa Costa

140
Battisti (2013, p. 32) obteve os seguintes resultados: a hipossegmentação é mais frequente com o clítico e seu hospedeiro dissílabo paroxítono; ocorre a consolidação da adjunção à direita de clíticos pronominais e não pronominais no século XIX; a hipossegmentação entre clíticos sugere que o pequeno corpo grafo-fônico dos clíticos procura satisfazer a exigência de minimalidade binária e, junto aos outros vocábulos em cadeia, contribuem para imprimir o ritmo fraco-forte ao enunciado; a hipossegmentação entre clítico e hospedeiro iniciado por maiúscula como indício de que o escrevente percebe o limite da palavra, mas assinala a dependência desse elemento em relação ao hospedeiro com a ausência de espaço em branco. A autora conclui que esse último resultado serve de evidência de que o constituinte resultante da prosodização ${ }^{9}$ do clítico não é a palavra fonológica, mas a frase fonológica.

\section{Metodologia}

Nesta seção, descreveremos os caminhos percorridos, desde a seleção do corpus até as dificuldades e soluções com as quais nos deparamos ao estabelecer as variáveis linguísticas e sócio-históricas deste estudo.

\subsection{A seleção do corpus}

O corpus desse trabalho é composto de 28 documentos manuscritos do Códice Geral de 1812 da Câmara Municipal de Rio Pardo, lotado no Arquivo Histórico Municipal Biágio Soares Tarantino (AHMRP). A criação do Arquivo data da constituição dos Departamentos Culturais do município no contexto da campanha de nacionalização do Estado Novo (1937-1945), quando foram instituídas as agências oficiais de preservação do patrimônio nacional (COSTA; REMEDI, 2013, p. 36-37). No entanto, teve início oficialmente em 29 de dezembro de 1992 pela Lei Municipal nº 162. No seu acervo, há aproximadamente 100 mil documentos registrados em manuscritos dos períodos colonial, imperial e republicano, compreendendo uma variedade de tipos documentais desde os registros oficiais da casa da Câmara Municipal, mapas, plantas, periódicos, iconografia, até as cartas e registros pessoais.

Realizamos a coleta dos documentos por meio da fotografia digital com uma câmera semiprofissional, sem o uso de flash e com a utilização de luvas descartáveis para não danificar o suporte. Em seguida, selecionamos

9 A prosodização consiste na incorporação fonológica dos clíticos a um vocábulo contíguo (BATTISTI, 2013, p. 19). 
os fac-símiles (imagens fotografadas dos manuscritos), dos escreventes que ocupavam um cargo na Câmara Municipal em 1812, conforme a qualidade da imagem, mais próxima possível do que se vê no documento genuíno, sem distorções ou qualquer aspecto fotográfico que dificulte a legibilidade do texto. Obtivemos, então, 15 documentos escritos pelo procurador da Câmara e 13 documentos do escrivão, totalizando 28 documentos.

Esses documentos foram classificados de acordo com a tipologia documental, dado que o campo de aplicação da tipologia se define pela relação dos documentos com as atividades institucionais (BELLOTTO, 2002, p. 19). Nesse caso, o tipo documental corresponderia à atividade administrativa de uma instituição como é o caso dos documentos emitidos no âmbito da Câmara Municipal. Após a análise do conjunto de manuscritos selecionados, classificamos os documentos em 14 ofícios, 2 recibos, 10 mandados, 1 termo de posse e 1 provisão.

Os manuscritos foram transcritos para a edição semidiplomática que, segundo Cambraia (2005, p. 128-129), pressupõe um grau médio de mediação, pois, no processo de reprodução do original, o editor realiza modificações como o desdobramento de sinais abreviativos, inserção ou supressão de elementos por conjectura.

\subsection{Perfil Sociocultural}

Na seção 3.1, a partir do estudo de Lopes et al. (2010), enfatizamos que a concepção do perfil sociocultural em trabalhos com registros escritos em sincronias passadas deve considerar o contexto de produção dos textos, o mapeamento e descrição das redes de escrita. Orientados pelas perguntas "Quem? Para quem? O modo de circulação? Onde? Quando?", obtemos informações gerais que se aplicam a ambos os escreventes: sexo masculino, ocuparam um cargo na Câmara Municipal e escreveram documentos numa relação profissional ascendente para o Senado e a Câmara. Esses documentos eram de circulação oficial, no âmbito da administração pública, precisamente, na Câmara Municipal da cidade de Rio Pardo em 1812, muito provavelmente escritos no próprio estabelecimento da esfera pública administrativa.

A identificação das demais variáveis sócio-históricas exigiu a consulta à documentação indireta e aos estudos sobre a cidade de Rio Pardo ${ }^{10}$. Além do Arquivo Histórico Municipal (AHMRP), visitamos o Arquivo His-

10 Cf. "A arte de governar: Redes de poder e relações familiares entre os juízes almotacés na Câmara Municipal de Rio Pardo/RS, 1811 - c. 1830”, de Schmachtenberg (2012). 
Leici Landherr

Moreira

Evellyne

Patrícia

Figueiredo de

Sousa Costa

142

tórico da Cúria Metropolitana (AHCM), em que localizamos os registros de casamento dos escreventes e o Arquivo Público do Rio Grande do Sul (APERS), onde consultamos o inventário de um dos escreventes. Os dados nos revelaram que Leocadio e Manoel ocupavam um cargo na Câmara Municipal de Rio Pardo em 1812, e por isso, eram homens maiores de 25 anos, casados ou emancipados, católicos, sem nenhuma "impureza de sangue" (mestiçagem racial) e proprietários de terra.

Leocadio Maximo de Souza ocupou o cargo de escrivão da Câmara Municipal de Rio Pardo, de 1811 a 1813. Leocadio era filho legítimo de Francisco de Souza Araujo e Ermenenciana Angelica do Sacramento. De nacionalidade brasileira, natural do Rio de Janeiro, foi batizado na Matriz Santo Antônio de Sá do Bispado do Rio de Janeiro. Em 22 de abril de 1805, na Matriz de Rio Pardo, casou-se com Anna Jachinta, natural de Rio Pardo, filha legítima de Manoel Antônio da Silveira e Maria Jachinta. ${ }^{11}$ Leocadio e Anna tiveram cinco filhos: Militão Maximo de Souza, Franscisco Maximo de Souza, Diogo Maximo de Souza, Fernando Maximo de Souza e Antonio Maximo de Souza. No inventário sobre os bens de Leocadio, não há menção sobre grandes posses de terra, apesar disso, o escrivão possuía alguns escravos, casa e uma botica. 0 escrivão faleceu em 27 de agosto de $1826 .{ }^{12}$

Manoel Bento Ferreira da Gama era estancieiro e Capitão da $2^{\mathrm{a}}$ Companhia do Terço de Ordenanças (SCHMACHTENBERG, 2012, p. 88, 245), e assumiu os cargos de: juiz almotacé em 1813 e 1815, juiz ordinário em 1819, vereador em 1814 e procurador em 1812 (SCHMACHTENBERG, 2012, p. 277). Natural da cidade do Porto (SCHMACHTENBERG, 2012, p. 246), casou-se em 9 de outubro de 1794 na Matriz de Rio Pardo, com Anna Maria do Rozario ${ }^{13}$, e não deixou herdeiros (SCHMACHTENBERG, 2012, p. 246). Schmachtenberg (2012, p. 245) explica que além do prestígio social perante a sociedade de Rio Pardo, o capitão possuía um grande patrimônio constituído, principalmente, de várias propriedades (SCHMACHTENBERG, 2012, p. 246).

Pelos cargos que ocuparam na Câmara, notamos que as funções de ambos os escreventes exigiam a prática de escrita frequente, o conhecimento da estrutura dos documentos, das fórmulas de escrita utilizadas em cada um deles.

11 Livro de Registro de Casamento III, Paróquia Nossa Senhora do Rosario (1762 - 1896). AHCM. 12 Processo judicial/inventário n904, 01/01/1826. APERS.

13 Livro de Registro de Casamento III, Paróquia Nossa Senhora do Rosario (1762 - 1896). AHCM. 


\subsection{Variáveis consideradas}

Para a análise do fenômeno de hipossegmentação, consideramos variáveis linguísticas de ordem prosódica propostas por Battisti (2013):

a) natureza das palavras que compõem a hipossegmentação, se clítico, palavra lexical, palavra funcional;

b) distribuição silábica e acentuação da palavra lexical e funcional; Variação

c) posição do clítico em relação à palavra lexical e funcional;

d) presença ou não de sândi vocálico externo ${ }^{14}$;

e) se a palavra lexical inicia com consoante ou vogal maiúsculas ou minúsculas.

gráfica em manuscritos oitocentistas da câmara municipal de Rio Pardo (RS)

Estabelecemos as seguintes variáveis sócio-históricas:

f) cargo;

g) tipo de documento;

h) aspectos paleográficos da escrita (análise da forma, nexo e uniões das letras por meio da sistematização de um alfabeto que contemple as letras maiúsculas e minúsculas localizadas nas fronteiras entre as palavras das formas hipossegmentadas);

i) domínio da escrita.

\section{Apresentação e discussão dos dados}

Selecionamos 410 ocorrências de formas hipossegmentadas e as classificamos de acordo com as variáveis estabelecidas.

a) Natureza das palavras que compõem a hipossegmentação.

Classificamos os dados em clítico + clítico (selhe), clítico + palavra lexical (ooficio), clítico + palavra funcional (amesma), palavra lexical + clítico (Pareseme), clítico + clítico + palavra lexical (selheabrir), clítico + clítico + palavra funcional (eporisso), palavra lexical + palavra lexical (ManoelBento), clítico + clítico + clítico (eselhe), clítico + palavra lexical + clítico (empagarse). A predominância é de hipossegmentação com clítico e palavra lexical, em 246 ocorrências.

\footnotetext{
14 De acordo com Bisol (2014), o sândi vocálico externo compreende os fenômenos de elisão, degeminação e ditongação. A elisão somente ocorre entre duas palavras fonológicas, logo, o clítico receberia também o status de unidade fonológica, indicando certa independência. Tal regra consiste no apagamento da vogal "a", quando a palavra seguinte começa por qualquer vogal que não seja "a", por exemplo, [uma hotelaria]C elide em [umotelaria]. Com a elisão, o clítico perde totalmente sua independência e pela reestruturação silábica torna-se, com a palavra de conteúdo adjacente, uma unidade só. Portanto, para considerarmos uma forma hipossegmentada com clítico como a representação do grupo clítico, a hipossegmentação deve apresentar o processo de elisão.
} 
Leici Landherr

Moreira

Evellyne

Patrícia

Figueiredo de

Sousa Costa

144

b) Distribuição silábica e acentuação da palavra lexical e funcional.

Selecionamos 370 dados e os classificamos em: proparoxítona trissílaba (daCamara), paroxítona polissílaba (aoSuplicante), paroxítona trissílaba (oOficio), paroxítona dissílaba (doAnno), oxítona polissílaba (eiducaçaô), oxítona trissílaba (aCertidaô), oxítona dissílaba (arazaó), monossílaba tônica (etres). Predominam hospedeiros paroxítonos dissílabos (118), seguidos de paroxítonos trissílabos (80) e monossílabos tônicos (69).

c) Posição do clítico em relação à palavra lexical e funcional.

Consideramos 351 ocorrências de hipossegmentação e a análise dos dados revelou a predominância de hipossegmentação com clíticos situados à esquerda do hospedeiro, i.e. adjunção do clítico para a direita (seacharáo, oescrevy, sepague, seselebrou).

d) Presença ou não de sândi vocálico externo.

Não localizamos nenhuma ocorrência de sândi vocálico externo.

e) Se a palavra lexical ou funcional inicia com consoante ou vogal maiúsculas ou minúsculas.

Selecionamos 390 dados, porque desconsideramos as hipossegmentações entre palavras lexicais e de palavra lexical + clítico. O resultado indicou a predominância de hospedeiros iniciados por consoante (naCaza, aSuplicada, doCostume, aCertidaô). De fato, é um número significativo, principalmente, se adotamos o ponto de vista de Battisti (2013) sobre as hipossegmentações de clítico + hospedeiro com inicial maiúscula. Segundo a autora (2013, p. 31), essas ocorrências permitem afirmar que o escrevente percebe a existência do hospedeiro e do clítico, que não é parte do hospedeiro, nem uma de suas sílabas pretônicas como seria se o clítico e hospedeiro constituíssem uma palavra fonológica. $\mathrm{O}$ fato de o hospedeiro iniciar com letra maiúscula pode ser um indício de que o clítico seja um elemento prosodicamente dependente do hospedeiro, com quem formaria uma frase fonológica. Como não localizamos dados de sândi vocálico externo, não há indícios de prosodização do clítico no nível do grupo clítico. 
f) Cargo.

Manoel Bento Ferreira da Gama era procurador e Leocadio Maximo de Souza ocupava o cargo de escrivão. Em virtude dos cargos que ocupavam, a escrita fazia parte de suas funções, principalmente para o escrivão. Leocadio exerceu essa ocupação durante o triênio 1811-1813, e por esse motivo já possuía contato com o ato de escrever há, no mínimo, um ano. Nesse sentido, a variável sócio-histórica de cargo/ocupação/profissão é muito importante, pois, se não há como verificar o nível de escolaridade desses escreventes, podemos, de outro modo, evidenciar que existe familiaridade com a escrita. Leocádio é responsável por $41 \%$ das ocorrências de hipossegmentações nos documentos, enquanto Manoel é responsável pela realização de 59\%.

Variação gráfica em manuscritos oitocentistas da câmara municipal de Rio Pardo (RS)

g) Tipo de documento. ${ }^{15}$

Examinamos os casos de hipossegmentação em cada tipo documental e os resultados apontaram que o fenômeno predomina nos ofícios e mandado, enquanto provisão, termo de posse e recibo possuem número menor de ocorrência. Costa e Pereira (2019, p. 132), ao analisarem a ocorrência de fenômenos fonológicos em espécies documentais escritas em Santana do Livramento (RS), apresentaram uma figura com uma gradiência, em que o título de eleitor apresentava o menor número de ocorrências de fenômenos fonológicos, enquanto a ordem do dia registrava o maior número. De acordo com as autoras (2019, p. 132), isso se deve à estrutura textual do documento. $\mathrm{O}$ título de eleitor possui uma forma pré-pronta e texto modelar, ao passo que na ordem do dia apesar da forma pré-pronta de abertura e desfecho do texto, o conteúdo textual apresenta diversos temas que são expostos de forma descritivo-narrativa. Nos documentos que compõem o corpus desta pesquisa, observamos que os ofícios exibem uma narrativa, apresentando maiores condições para o aparecimento de hipossegmentações, ao contrário dos recibos, que contém uma narrativa limitada, mais próxima de uma forma pré-estabelecida. Mesmo assim, ficou evidente que as hipossegmentações ocorrem em todos os tipos documentais.

15 Para uma descrição detalhada de cada tipo documental, conferir Moreira (2019). 


\section{Leici Landherr}

Moreira

Evellyne

Patrícia

Figueiredo de

Sousa Costa

146

h) Aspectos paleográficos da escrita.

A paleografia é o "estudo das escritas antigas" (CAMBRAIA, 2005, p. 23, grifo do autor). Para o crítico textual, informações de natureza paleográfica são muito importantes uma vez que possibilitam o entendimento da leitura das fontes. Uma das informações a serem consideradas pelo crítico textual é a descrição de características da escrita, que, conforme Cambraia (2005, p. 24), são: a morfologia das letras, o seu traçado ou ductus, o ângulo, o módulo e o peso. Com base nesses aspectos, estudiosos tais como Fachin (2006), Mateus (2016) e Gonçalves (2018) realizam o levantamento do alfabeto empregado nos textos que compõem corpora histórico-diacrônicos com vistas a facilitar a interpretação do manuscrito.

Neste trabalho, o levantamento do alfabeto utilizado por cada um dos escreventes auxilia a compreensão de seus hábitos gráficos, possibilitando a caracterização das hipossegmentações. Por isso, não elaboramos um alfabeto completo que contemple a distribuição dos grafemas maiúsculos e minúsculos em contexto inicial, medial e final, mas apresentamos uma versão sintética, com as letras maiúsculas e minúsculas localizadas nas fronteiras entre as palavras das formas hipossegmentadas ${ }^{16}$.

Os resultados de análise do alfabeto empregado por Manoel Bento Ferreira da Gama indicaram o uso de escrita cursiva pelo redator, mas nem todas as letras se apresentaram ligadas umas às outras. Percebemos que o traçado das letras minúsculas $t, q, r, s$, d, 1 não é contínuo e não há ligadura em nenhum aspecto. Essa ausência de ligação raramente ocorre na fronteira entre duas palavras, onde as letras minúsculas o, a, e, m, escritas no final da primeira palavra, apresentam traçado contínuo. $O$ ato de escrever de Manoel Bento Ferreira da Gama evidencia que a escrita de formas hipossegmentadas não parece estar relacionada somente ao traçado contínuo da pena e ao fluxo da escrita cursiva, mas, especialmente, à forma do elemento gráfico. Parece que o traça-

16 Os quadros elaborados com o alfabeto utilizado por Manoel Ferreira da Gama e Leocadio Maximo de Souza podem ser conferidos em Moreira (2019), p. 141, e p. 143, respectivamente. 
do contínuo ou não de uma letra influencia a ausência de espaço em branco na fronteira vocabular. Também verificamos que a ligação sempre ocorre com clíticos + palavras lexicais/ funcionais, ao contrário da união de palavras lexicais que ora se apresentam ligadas umas às outras, ora não.

Variação gráfica em

Por outro lado, o traçado das letras escritas por Leocádio Mamanuscritos ximo de Souza é mais contínuo do que o verificado em Manoel oitocentistas Bento Ferreira da Gama, sendo poucas ocorrências de letras que da câmara não se apresentam ligadas umas às outras. Por esse motivo, as municipal de hipossegmentações podem ser justificadas pelo fato de a letra do Rio Pardo (RS) escrevente possuir um traçado corrente à mão. Apesar do encadeamento da letra cursiva não se definir por critérios gramaticais, parece que, quando se trata de ausência de fronteira entre palavras, também há preferência por clíticos.

i) Domínio da escrita.

Já mencionamos anteriormente a dificuldade de determinar o grau de escolaridade dos escreventes, mas como a prática da escrita fazia parte das funções exercidas pelos indivíduos que ocupavam um cargo na Câmera, torna-se possível levantar hipóteses sobre seu domínio de escrita por meio do conhecimento da estrutura do documento e das fórmulas de escrita utilizadas em cada um deles.

A familiaridade com a escrita já é evidente, pois os escreventes ocupavam o cargo já há algum tempo. E a classificação dos documentos em tipos que, apesar de alguns documentos não possuírem obrigatoriamente a estrutura pré-estabelecida para os documentos de hoje, de modo geral, apresentam características comuns muito próximas da forma padronizada, especialmente, formas que se mostram recorrentes em todos os documentos que pertencem ao mesmo tipo documental. Os recibos escritos por Manoel e Leocadio, por exemplo, apresentam a mesma estrutura: no início do documento a expressão "Recebi do(a)", seguida do texto, indicação de data tópica e cronológica, e assinatura. 


\section{Leici Landherr}

Moreira

Evellyne

Patrícia

Figueiredo de

Sousa Costa

Além disso, não localizamos ausência de cursus, módulo grande, ausência de regramento, traçado inseguro nem letras com aparência desenquadrada. Os manuscritos estão escritos com base num regramento uniforme, com margens padronizadas de todos os lados do fólio, características que indicam contato frequente com essa prática de escrita. Por esses aspectos, podemos dizer que os dois escreventes dominavam a escrita.

\subsection{Análise dos resultados}

A proposta deste trabalho era verificar se a ocorrência da variação gráfica de hipossegmentação estava associada a uma motivação que envolvesse condicionadores linguísticos de ordem prosódica e fatores sócio-históricos. Os resultados da análise de variáveis linguísticas revelaram que as hipossegmentações caracterizam-se por ocorrerem predominantemente (i) com clíticos e palavras lexicais, (ii) com hospedeiros paroxítonos dissilábicos, paroxítonos trissilábicos, e com monossílabos tônicos, todos iniciados por consoante, (iii) com clíticos adjungidos à direita do hospedeiro. 0 número significativo de hipossegmentações de clítico + hospedeiro iniciado com consoante maiúscula permitiu que chegássemos à motivação linguística para o fenômeno estudado: o escrevente percebe a existência do hospedeiro e do clítico, mas assinala a dependência prosódica do clítico em relação ao hospedeiro, registrando, assim, uma frase fonológica.

Pelos resultados obtidos na análise das variáveis sócio-históricas, constatamos que os escreventes apresentavam familiaridade com o ato de escrever por conta de lidarem com a escrita no âmbito das funções exigidas pelo cargo, e pelo motivo de demostrarem conhecer a estrutura dos documentos e das fórmulas de escrita utilizadas em cada um deles. Por essas razões, e pela ocorrência de formas hipossegmentadas em todos os tipos documentais, podemos dizer que o registro de formas hipossegmentadas pode ser uma característica da prática de escrita dos documentos oficiais e administrativos escritos em Rio Pardo por Manoel e Leocadio em 1812.

Os resultados de análise da variável paleográfica corroboraram com essa hipótese e permitiram identificar a motivação sócio-histórica para esse tipo de fenômeno: a forma do elemento gráfico, se possui ou não traçado contínuo, pode influenciar na formação de hipossegmentações. Além disso, nessas formas hipossegmentadas, a ligação na jun- 
ção da fronteira vocabular ocorre, majoritariamente, com clíticos, e por isso, é possível dizer que a ligação de uma palavra lexical com clítico poderia ser uma forma de escrita pré-estabelecida e já fixada como particularidade gráfica dos escreventes.

\section{Conclusão}

Buscamos, desde o início deste trabalho, analisar as hipossegmentações em manuscritos selecionados do Códice Geral de 1812 da Câmara Municipal de Rio Pardo a fim de identificar uma motivação para a ocorrência desse fenômeno que envolvesse condicionadores linguísticos de ordem prosódica e fatores sócio-históricos. Sob o aporte teórico da Sociolinguística Histórica, valendo-se de estudos da filologia e da paleografia, nos propomos a fazer o "melhor uso dos dados disponíveis" (NEVAVariação gráfica em manuscritos oitocentistas da câmara municipal de Rio Pardo (RS) LAINEN; RAUMOLIN-BRUNBERG, 2017). E por isso, desenvolvemos uma proposta metodológica para o estudo de fenômenos linguísticos em documentos oficiais da Câmara Municipal de Rio Pardo, que combinou a coleta, seleção e edição de documentos, identificação/reconstrução de variáveis sócio-históricas por meio da busca nos Arquivos do Estado, e o estabelecimento das variáveis linguísticas e sócio-históricas efetivamente produtivas para a análise dos dados. Os resultados não só confirmaram a existência de uma motivação linguística de ordem prosódica e de uma motivação sócio-histórica de ordem paleográfica para o fenômeno de hipossegmentação, mas também nos levaram a algumas reflexões teórico-metodológicas para os estudos de língua portuguesa em tempos pretéritos, sobretudo, na Rio Pardo oitocentista.

Apesar da escolha pela constituição de um corpus de documentos oficiais não ser muito comum em estudos que considerem a sócio-história do português no Brasil, em nosso trabalho, procuramos insistir na contribuição dos documentos oficiais para os trabalhos de Sociolinguística Histórica, principalmente, para a reconstrução de variáveis sócio-históricas. Notamos que quando o escrevente faz parte da vida pública da sociedade, como aqueles que ocupavam um cargo na Câmara por preencherem o requisito de integrar a elite socioeconômica local, há grande probabilidade de localizar documentos acerca de seus dados biográficos.

A elaboração de procedimentos metodológicos adaptados à particularidade do corpus nos levou ao estabelecimento de duas premissas para o trabalho com corpora histórico-diacrônicos. A primeira diz respeito ao exame meticuloso do texto que precede à fixação de variáveis lin- 
Leici Landherr

Moreira

Evellyne

Patrícia

Figueiredo de

Sousa Costa

guísticas, sócio-históricas. A segunda, é sobre a reconstrução de variáveis sócio-históricas, que está sujeita à construção de um perfil sociocultural que articule o contexto de produção dos textos, a prática de escrita dos informantes e as variáveis sociais identificadas na documentação indireta. Percorremos um "caminho arquivístico" pelo AHMRP, AHCM e APERS no intuito de localizar informações biográficas dos escreventes. A despeito das limitações, construímos o perfil sociocultural. Acreditamos, portanto, que esse procedimento metodológico possa ser aplicado em outros trabalhos com corpora de documentos oficiais em todo o estado. Esperamos que esse trabalho tenha contribuído para os estudos de língua portuguesa em tempos pretéritos no Rio Grande do Sul.

\section{REFERÊNCIAS}

ABAURRE, M.B.M. O que revelam os textos espontâneos sobre a representação que faz a criança do objeto escrito? In: KATO, M. (Org.) A concepção da escrita pela criança. Campinas: Pontes, 1992.

ARGOTE, J. Contador de. Regras da Lingua Portugueza, Espelho da Lingua Latina, ou disposiçaõ para facilitar o ensino da lingua Latina pelas regras da Portugueza. Lisboa Occidental: Officina da Musica, 1725.

BARBOSA, A. G. Fontes escritas e história da língua portuguesa no Brasil: as cartas de comércio no século XVIII. In: Ivana Stolze Lima; Laura do Carmo. (Org.). História social da língua nacional. Rio de Janeiro: Edições Casa de Rui Barbosa, 2008. p. 181-211.

BATTISTI, E. Aspectos prosódicos do português brasileiro: Hipossegmentação de sequências com clíticos em documentos do século XIX. Revista do GELNE (UFC), v. 15, p. 13-30, 2013.

BELLOTTO, H. L. Como fazer análise diplomática e análise tipológica de documento de arquivo. São Paulo: Arquivo do Estado, Imprensa Oficial, 2002.

BISOL, L. O clítico e seu hospedeiro. Letras de Hoje, EDIPUCRS, v. 40, n.3, p. 163-184, 2005. 
CÂMARA JUNIOR, M. Princípios de Linguística Geral. Rio de Janeiro: Livraria Acadêmica, 1964.

CAMBRAIA, C. N. Introdução à crítica textual. São Paulo: Martins Fontes, 2005.

Variação gráfica em

CARNEIRO, Z. de O. N. Cartas brasileiras (1808-1904): Um estudo manuscritos linguístico filológico. Tese (Doutorado em Letras). Instituto de Estudos da Linguagem, Universidade Estadual de Campinas, Campinas, SP, 2005. oitocentistas da câmara municipal de Rio Pardo (RS)

COMISSOLI, A. Os "homnes bons" e a Câmara de Porto Alegre (17671808). Dissertação (Mestrado em História). Programa de Pós-Graduação em História, Universidade Federal Fluminense. Niterói, RJ, 2006.

CONDE-SILVESTRE, J. C. Sociolinguística Histórica. Madrid: Gredos, 2007.

COSTA, E. P. F de S; PEREIRA, V. Manuscritos do séc. XIX: processos fonológicos ontem e hoje. Polifonia: estudos da linguagem, v. 26, p. 119-141, 2019.

COSTA, M. Â. S.; REMEDI, J. M. R. Em nome dos valiosos testemunhos de nossas caras tradições: a "invenção" da cidade monumento e a polêmica patrimonialização da Rua da Ladeira - Rio Pardo. Patrimônio e Memória, 9, 2013, p. 31-55.

CUNHA, A. P. N. da; MIRANDA, A. R. M. A hipo e a hipersegmentação nos dados de aquisição de escrita: a influência da prosódia. Alfa, São Paulo, 53, n. 1, p. 127-148, 2009.

ESTEBAN- SEGURA, L. Medical, official, and Monastic Documents in Sociolinguistic. In: HERNÁNDEX-CAMPOY, J. M.; CONDE-SILVESTRE, J. C. The Handbook of Historical Sociolinguistics. Oxford: Blackwell, 2012. p. 140-155.

FACHIN, P. M. Estudo paleográfico e edição semidiplomática de manuscritos do Conselho Ultramarino. Dissertação (Mestrado em Filologia e Língua Portuguesa). Universidade de São Paulo. São Paulo, 2006. 
FACHIN, P. Práticas de escrita setecentista em manuscritos da administração colonial em circulação pública no Brasil. Tese (Doutorado em letras). Universidade de São Paulo. São Paulo, 2011.

Leici Landherr

Moreira

Evellyne

Patrícia

Figueiredo de

Sousa Costa

152
FEIJO, J. de M. M. Orthographia, ou arte de escrever, e pronunciar com acerto a lingua portugueza para uso do excellentissimo Duque de Lafoens / pelo seu mestre João de Moraes Madureyra Feyjo. Lisboa Occidental: Officina de Miguel Rodrigues, Impressor do Senhor Patriarca, 1734.

FERREIRO, E.; PONTECORVO, C. Os limites entre as palavras: a segmentação em palavras gráficas. In: FERREIRO, E. et alii. Chapeuzinho Vermelho aprende a escrever. São Paulo: Ática, 1996. p. 38-77.

GONÇALVES, E. C. B. Leitura crítico-filológica de Resolução de 1822: revoltas, vigilância, violência e punição na Bahia do século XIX. Filologia e Linguística Portuguesa. São Paulo, v. 20, n. 2, p. 153-174, 2018.

KAJITA, A. S. A segmentação inábil: um estudo da segmentação ortográfica não-canônica. 2009. Dissertação (Mestrado em Linguística). Instituto de Estudos da Linguagem, Universidade Estadual de Campinas. Campinas, 2009.

LABOV, W. The Use of the Present to Explain the Past. In: LABOV, W. Principles of Linguistic Change: Internal Factors. Oxford: Blackwell, 1999, p. 9-27.

LAYTANO, D. de. Almanaque de Rio Pardo. Porto Alegre: Editora Oficinas gráficas da Tip. do Centro, 1976.

Livro de Atas de 1818/1821, f. 168v a 170. AHMRP.

Livro de Posses e Juramentos (LPJ), n. 2, 1811/1841.

Livro de Registro de Casamento III, Paróquia Nossa Senhora do Rosario (1762 - 1896). AHCM. 
LOPES, C. R. dos S.; RUMEU, M. C. de B.; MARCOTULIO, L. L.; LIMA, A. X. Reflexões metodológicas para a análise sociocultural de redatores em corpora históricos. Gragoatá (UFF), v. 29, p. 239-253, 2010.

MATEUS, E. T. Os "papéis velhos" na rede: manuscritos digitaliVariação gráfica em zados e a leitura paleográfica. AEDOS, Porto Alegre, v. 8, n. 18, p. 26-51. 2016.

manuscritos oitocentistas da câmara

MEGAle, H.; TOLEDO NETTO, S. A.; FERREIRA, A. H.; SOUZA, E. C. C. municipal de A leitura de manuscritos em português: documentação do século Rio Pardo (RS) XVII. In: MURAKAWA, C. de. A. A; GONÇALVES, M. F. (Org.) Novas contribuições para o estudo da história e da historiografia da língua portuguesa. Araraquara: Cultura Acadêmica, 2007, v. 11, p. 127-158.

MOREIRA, L. L. Hipossegmentações em manuscritos oitocentistas da Câmara Municipal de Rio Pardo (RS). Dissertação (Mestrado em Letras). Programa de Pós-Graduação em Letras, Universidade Federal de Santa Maria. Santa Maria, RS, 2019.

GONÇALVES, M. F. (Org.). Novas contribuições para o estudo da história e da historiografia da língua portuguesa. Araraquara: Cultura Acadêmica, 2007, v. 11, p. 127-158.

MEISTER, R. História do Município de Rio Pardo. Disponível em: https://riopardo.rs.gov.br/turismo/2017/03/21/historia-do-municipio-de-rio-pardo/. Acesso em: 26 de setembro de 2018.

MENDES, S. T. do P.; DORES, M. V. P. das; GOMES, M. F. Apontamentos paleográficos e análise de indícios de mudança fonética em manuscrito setecentista de Minas Geraes. Filologia e Linguística Portuguesa. São Paulo, v. 19, n. 1, p. 33-56, 2017.

MONARETTO, V. O estudo da mudança de som no registro escrito: fonte para o estudo da fonologia diacrônica. Letras de Hoje, Porto Alegre, v. 40, n. 3, 2005. 
Leici Landherr

Moreira

Evellyne

Patrícia

Figueiredo de

Sousa Costa
MONTE CARMELO, L. de. Compendio de orthografia, com sufficientes catalogos, e novas regras, para que em todas as Provincias, e Dominios de Portugal, possam os curiosos comprehender facilmente a Orthologia, e Prosódia, isto he, a recta pronunciaçam, e accentos proprios, da Lingua Portugueza: accrescentado com outros novos Catalogos, e explicaçam de muitos Vocabulos antigos, e antiquados, para intelligencia dos antigos escritores portuguezes. Lisboa: Officina de Antonio Rodrigues Galhardo, 1767.

MORALES, F. M. Problemas metodológicos de la sociolinguística histórica. Forma y función. Bogotá, v. 18, p. 115-137, 2005.

NASI, R. F. Elevação das Vogais Médias Pretônicas no Português sul-rio-grandense: retrato oitocentista e alternativa de interpretação do grafema como indício fonético/fonológico. Tese (Doutorado em Letras). Programa de Pós-Graduação em Letras, Universidade Federal do Rio Grande do Sul. Porto Alegre, RS, 2016.

NASI, R. F. Variáveis fonológicas em jornais gaúchos do século XIX. Dissertação (Mestrado em Letras). Programa de Pós-Graduação em Letras, Universidade Federal do Rio Grande do Sul. Porto Alegre, RS, 2012.

NESPOR, M., VOGEL, I. Prosodic Phonology. Dordrecht: Foris Publications, [1986] 2007.

NEVALAINEN, T.; RAUMOLIN-BRUNBERG, H. Historical Sociolinguistics: Language change in Tudor and Stuart England. London: Routledge Taylor \& Francis Group, 2017.

PEREIRA, V. V. Caracterização da língua portuguesa da segunda metade do século XIX na região da fronteira (Santana do Livramento/Rivera). Dissertação (Mestrado em Estudos Linguísticos). Programa de Pós-Graduação em Letras, Universidade Federal de Santa Maria. Santa Maria, 2017.

Processo judicial/inventário nº904, 01/01/1826. APERS. 
RIBEIRO, T. J. S. Variação das vogais médias pretônicas em textos antigos: contribuições da teoria neogramática e da difusão lexical. Dissertação (Mestrado em Estudos Linguísticos). Programa de Pós-Graduação em Letras, Universidade Federal de Santa Maria. Santa Maria, 2018.

ROMAINE, S. Socio-historical linguistics: its status and methodology. Cambridge: Cambridge University Press, [1982] 2009.

SCHMACHTENBERG, R. "A arte de governar": Redes de poder e relações familiares entre os juízes almotacés na Câmara Municipal de Rio Pardo/RS, 1811 - c.1830. Tese (Doutorado em História). Programa de Pós-Graduação em História, UNISINOS. São Leopoldo, 2012.

Variação gráfica em manuscritos oitocentistas da câmara municipal de Rio Pardo (RS)

SCHMACHTENBERG, R. Entre a vida pública e a vida privada: José Joaquim de Figueiredo Neves, redes de poder e relações familiares na Vila de Rio Pardo, Província do Rio Grande de São Pedro (18001830) In: REMEDI, J. M. R. (Org.) Na fronteira do Império: política e sociedade na Rio Pardo oitocentista. Santa Cruz do Sul: EDUNISC, 2018.

SILVA, R. S. da. Português Gaúcho Oitocentista: levantamento de algumas formas linguísticas. Trabalho de Conclusão de Curso (Graduação em Letras - Inglês). Universidade Federal do Rio Grande do Sul. Porto Alegre, RS, 2013.

SPINA, S. Introdução à edótica: crítica textual. São Paulo: Cultrix, 1977.

TELLES, C. M.; LOSE, A. D. Escrita e fala: o que nos ensinam os textos não literários. Línguas \& Letras (Online), v. 11, p. 1-19, 2010.

VOGT, O. P.; ROMERO, M. R. Z. (Org.). Uma luz para a história do Rio Grande: Rio Pardo 200 anos: cultura, arte e memória. Santa Cruz: Editora Gazeta Santa Cruz, 2010. 
